\title{
ATIVISMO JUDICIAL: NOS LIMITES ENTRE RACIONALIDADE JURÍDICA E DECISÃO POLÍTICA
}

\author{
Anderson Vichinkeski Teixeira
}

JUDICIAL ACTIVISM: IN THE LIMITS BETWEEN LEGAL RATIONALITY AND POLITICAL DECISION

\section{RESUMO}

O PRESENTE ARTIGO TEM COMO OBJETIVO ENCONTRAR PARÂMETROS PARA QUE SE POSSA DETERMINAR QUANDO ATIVISMO JUDICIAL DEIXA O ÂMBITO DA ARGUMENTAÇĀO JURÍDICA E SE torna instrumento de decisão política. Para tanto, TENTAMOS DEFINIR UM POSSÍVEL CONCEITO DE ATIVISMO JUDICIAL E AS SUAS ORIGENS NA TRADIC̣ÃO JURÍDICA ESTADUNIDENSE. NESSE PRIMEIRO MOMENTO UTILIZAMOS O MÉTODO HISTÓRICOANALÍTICO PARA CONTEXTUALIZAR HISTORICAMENTE AS CATEGORIAS CONCEITUAIS EM ESTUDO E O MOMENTO DE SURGIMENTO DO FENÔMENO NOS ESTADOS Unidos. EM SEguida, PASSAMOS A ESTUDAR, COM BASE NO MÉTODO CRÍTICO-COMPARATIVO, OS ELEMENTOS FUNDAMENTAIS QUE CARACTERIZAM A RACIONALIDADE POLÍTICA E A RACIONALIDADE JURÍDICA. AO FINAL, DISCUTIMOS AS PERSPECTIVAS PARA UM JUIZ ATIVISTA NO BRASIL, ESPECIALMENTE QUANDO ATUE NA PROTECÃO DOS DIREITOS FUNDAMENTAIS E NA gARANTIA DA SUPREMACIA DA CONSTITUIÇÃO. EM TERMOS GERAIS, NOSSAS CONCLUSÕES APONTAM CRITÉRIOS QUE PERMITAM A DEFINIÇÃO DO QUE SERIA UM ATIVISMO JUDICIAL POSITIVO, EM DETRIMENTO DA SUA ESPÉCIE NOCIVA À SAÚDE DA ORDEM CONSTITUCIONAL.

\section{PALAVRAS-CHAVE}

DIREITO CONSTITUCIONAL; DECISÃO JURÍDICA; DECISÃO POLÍTICA; ARGUMENTAÇÃO JURÍDICA; ATIVISMO JUDICIAL.

\section{ABSTRACT}

THIS ARTICLE HAS AS GENERAL GOAL TO FIND PARAMETERS IN ORDER TO DETERMINE WHEN THE JUDICIAL ACTIVISM LEAVES THE FIELD OF LEGAL ARGUMENTATION AND BECOMES AN INSTRUMENT OF POLITICAL DECISION. TO THIS END, WE STARTED TRYING TO DEFINE A POSSIBLE CONCEPT OF JUDICIAL ACTIVISM AND ITS ORIGINS IN THE UNITED STATES JURIDICAL TRADITION. IN THIS FIRST MOMENT, WE USE THE HISTORICAL ANALYTICAL METHOD TO TRY TO CONTEXTUALIZE HISTORICALLY THE CONCEPTUAL CATEGORIES UNDER STUDY AND THE CONDITIONS OF EMERGENCE OF THIS PHENOMENON IN THE UNITED STATES. FOLLOWING, ON THE BASIS OF THE CRITICAL COMPARATIVE METHOD, WE BEGAN TO STUDY THE FUNDAMENTAL ELEMENTS THAT CHARACTERIZE POLITICAL RATIONALITY AND LEGAL RATIONALITY. AT THE END, WE DISCUSS THE PROSPECTS FOR AN ACTIVIST JUDGE IN BRAZIL, ESPECIALLY WHEN ACTING IN THE PROTECTION OF FUNDAMENTAL RIGHTS AND ENSURING THE SUPREMACY OF THE CONSTITUTION. IN GENERAL TERMS, OUR CONCLUSIONS POINTS TO A SET OF CRITERIA FOR THE DEFINITION OF WHAT WOULD BE A SO-CALLED POSITIVE JUDICIAL ACTIVISM, TO THE DETRIMENT OF ITS OTHER SORT THAT IS HARMFUL TO THE WEALTH OF THE CONSTITUTIONAL ORDER.

\section{KEYWORDS}

CONSTITUTIONAL LAW; LEGAL DECISION; POLITICAL DECISION; LEGAL ARGUMENTATION; JUDICIAL ACTIVISM.

\section{INTRODUÇÃO}

Uma das expressões mais correntes atualmente nas diversas áreas do saber jurídico, mesmo sem contar com definição precisa e origem exata, é o chamado "ativismo judicial". O sentido pejorativo é empregado em determinados momentos, enquanto, 
em outros, um juiz “ativista” termina representando a personificação daquele juiz Hércules do qual fala Dworkin. ${ }^{1}$ Embora a atenção da doutrina brasileira à expressão em tela possa ser considerada recente - os primeiros textos são posteriores à Constituição de 1988 -, os Estados Unidos incorporaram ao seu léxico político-jurídico o judicial activism desde o início do século XX.

A primeira aproximação teórica que se poderia fazer seria comparar o ativismo judicial com a criação judicial do Direito. ${ }^{2}$ Todavia, a compreensão acerca do poder criador (normativo) do juiz, atuando como instrumento em condições de atribuir dinâmica a um direito estático produzido pelo legislador, não apresenta grandes dificuldades quando comparado à vasta gama de complicações postas pelo ativismo judicial. Tais complicações vão muito além da Teoria do Direito e da Hermenêutica Jurídica - âmbitos teóricos em condições de enfrentar plenamente o tema da criação judicial do Direito: atingem a Política e a sua capacidade de legitimamente atender aos clamores populares na busca do bem comum. O ativismo judicial representa, em última instância, a deslegitimação da Política em relação à sua tarefa essencial de buscar a realização dos valores determinados pela sociedade no cotidiano dessa mesma sociedade. Corrupção, política como sinônimo de defesa de interesses meramente partidários, bem como burocratização estatal, são três componentes sociológicos que corroboram para fortalecer o mito do juiz Hércules no subconsciente coletivo e culminar na crescente judicialização das relações sociais.

Diante disso, neste artigo buscaremos, primeiramente, encontrar as origens do fenômeno em questão, de modo que possamos então determinar como ele trouxe para o Direito uma espécie de racionalidade que é própria da Política. Por fim, tentaremos sintetizar alguns limites já expostos pela doutrina comparatista ao ativismo judicial e suscitar outros possíveis.

\section{ORIGens do ATIVismo JUDicial}

Se afastarmos por completo qualquer possível comparação com a criação judicial do Direito ou com o judicial review (controle difuso de constitucionalidade das leis), encontraremos, certamente, nos Estados Unidos a origem do ativismo judicial. Mais precisamente, na decisão Lochner v. New York ${ }^{3}$ a Suprema Corte daquele país entendeu que o princípio de liberdade contratual estava implícito na noção de devido processo legal (due process of law) consagrada pela seção 1 da $14^{\mathrm{a}}$ Emenda à Constituição dos EUA. No caso em tela, a Corte declarou inconstitucional uma lei do Estado de Nova York que estabelecia 60 horas como limite para a jornada de trabalho semanal dos padeiros, alegando ser “'irrazoável', desnecessária e arbitrária” tal limitação à liberdade individual de contratar. ${ }^{4}$ Além de representar aquilo que veio a ser chamado de "Era Lochner" (1897-1937), na qual as intervenções estatais no domínio econômico foram continuamente invalidadas pela Suprema Corte dos EUA, pode 
ser considerado também um dos primeiros casos de flagrante ativismo judicial exercido por aquela Corte. ${ }^{5}$

Mas foi com o historiador Arthur Schlesinger Jr., em uma matéria da revista Fortune intitulada The Supreme Court: 1947, que o termo judicial activism entrou no léxico não apenas jurídico, mas sobretudo político e popular. ${ }^{6}$ Referindo à capacidade de desempenhar um papel afirmativo na promoção do bem-estar social, Schlesinger chamou de "ativistas judiciais" (judicial activists) os juízes Hugo Black, Willian O. Douglas, Frank Murphy e Wiley Rutledge. Já os juízes Felix Frankfurter, Harold Burton e Robert H. Jackson foram rotulados de "campeões do autocomedimento" (champions of self-restraint), por entenderem que o Judiciário não deve ir além do seu espaço limitado dentro do sistema estadunidense. Em uma posição intermediária, o presidente da Suprema Corte naquele ano, Frederick M. Vinson, e o juiz Stanley F. Reed não seriam plenamente caracterizáveis como desse ou daquele lado. ${ }^{7}$

Um aspecto fundamental do ativismo judicial que Schlesinger detectou imediatamente foi a maleabilidade do raciocínio jurídico em detrimento da sua cientificidade. Keenan D. Kmiec, ao comentar o artigo de Schlesinger, destaca que este já havia detectado que os judicial activists entendem como indissociáveis Direito e Política, o que impediria existir uma resposta "correta” em definitivo, pois toda decisão judicial importaria uma escolha política do julgador. ${ }^{8}$ Segundo essa perspectiva, o autocomedimento não passaria de um ilusória pretensão de objetividade no ato decisório, algo incompatível com o senso de justiça e o anseio por produzir melhoras sociais que devem nortear o julgador.

O famoso texto de Schlesinger nasce com dois problemas que parecem ter passado despercebidos aos olhos do autor: a imprecisão terminológica da expressão em debate e a indefinição quanto a ser algo positivo ou negativo. Ele rotula os juízes da Suprema Corte de "ativistas judiciais" e "campeões do autocomedimento", vincula características a cada um desses grupos, mas não deixa claro qual a melhor postura, seja do ponto de vista político ou jurídico. Em sentido semelhante ao exposto por Kmiec, ${ }^{9}$ vemos que o que Schlesinger já deixa claro são os conflitos internos que o ativismo judicial termina produzindo:

- Juízes não eleitos vs. leis democraticamente aprovadas;

- Decisões orientadas politicamente vs. decisões orientadas juridicamente;

- Uso criativo do precedente vs. uso estrito do precedente;

- Supremacia da vontade popular vs. direitos humanos;

- Política vs. Direito. 
Todavia, as dúvidas existentes quanto ao caráter positivo ou pejorativo da expressão foram reduzidas à medida que a postura "ativista" era incorporada por diversos juízes não apenas da Suprema Corte: durante a década de 1950 a jurisdição ordinária passou a desempenhar papel significativo na defesa dos direitos civis para as minorias sociais, sobretudo minorias raciais. ${ }^{10} \mathrm{O}$ expressivo crescimento de programas federais, durante o período do New Deal, demandava uma atenção específica para o impacto das suas ações nos contextos concretos das realidades locais, tornando o Judiciário espaço derradeiro no processo de garantia dos direitos das minorias. Surgiram então as ações afirmativas como instrumento político de combate à desigualdade social decorrente de fatores como sexo, raça, etnia, religião ou qualquer outra forma de discriminação. ${ }^{11}$ No governo do presidente Lyndon Johnson, o Civil Rights Act, de 1964, representou o primeiro passo de um programa social que naquele ano e no ano seguinte faria entrar em vigor uma série de leis cujos dois objetivos principais eram: auxiliar pessoas de baixa renda por meio de programas de incentivo à educação e de proteção à saúde, e estimular a economia para que novas vagas fossem abertas a pessoas que historicamente se encontravam excluídas, ou marginalizadas, dentro do sistema educacional e do mercado de trabalho. ${ }^{12}$ Foi nesse contexto que o ativismo judicial ganhou fôlego em solo estadunidense e passou a representar a defesa em juízo de ações que politicamente não se mostravam suficientes.

No Brasil, a temática relativa ao ativismo judicial só ganhou expressão com a entrada em vigor da Constituição de 1988, pois esta atribuiu uma série de prerrogativas ao magistrado, impulsionando-o, inevitavelmente, a uma atuação mais presente na sociedade e, em consequência, com maior repercussão midiática; veja-se, por exemplo, todos os milhares de casos em que se faz necessário assegurar direitos fundamentais que não encontram previsão legal em condições de lhes dar regulamentação. Uma característica própria do nosso período constitucional pós-1988 é a ampla possibilidade de utilização do controle abstrato de constitucionalidade. Desde o surgimento em solo brasileiro dessa modalidade de controle de legitimidade constitucional das leis ou atos normativos com força de lei, por meio da Emenda Constitucional n. 16, de 1965, ${ }^{13}$ à Constituição de 1946, deu-se um substantivo acréscimo no rol de legitimados ativos que hoje se encontram previstos no art. 103 do texto constitucional. Tal ampliação aumenta também a responsabilidade do Supremo Tribunal Federal em relação à legitimidade de políticas públicas e medidas sociais que encontram na legislação o seu meio natural de implementação. Um debate (sobre a constitucionalidade das leis), que antes de 1965 ficava primordialmente concentrado no meio político, hoje concentra-se cada vez mais nas instâncias judiciais ordinárias, que estão em condições de exercer o controle difuso, mas também concentra-se, derradeiramente, naquilo que é decidido no juízo abstrato do Supremo Tribunal Federal.

Se, por um lado, a crescente judicialização das relações sociais é resultado do aumento de questões políticas que passaram a ser discutidas também em juízo, vemos, 
por outro lado, a pressão dos diversos processos de globalização culminar na complexização das relações sociais e na necessidade de se recorrer ao Judiciário para a resolução de conflitos que outrora eram resolvidos nas demais esferas da sociedade. Diante disso, o ativismo judicial nasce em um cenário de alto complexização social e consequente fragmentação das tradicionais estruturas "a-jurídicas" (como morais e religiosas, por exemplo) de resolução das controvérsias, de modo que podemos distinguir dois pressupostos fenomenológicos fundamentais ao ativismo judicial: reificação e judicialização; esta em uma perspectiva político-institucional, aquela em uma perspectiva sociológica.

Primeiramente, a reificação, segundo definição de Axel Honneth, é o "esquecimento do reconhecimento", ${ }^{14}$ isto é, as diversas formas de reconhecimento, responsáveis por atribuir identidade aos indivíduos e gerar reciprocidade nas suas relações interpessoais, passaram a ser acometidas por um processo de "coisificação" que tem como causa maior - única, segundo Honneth - a "generalização, na era capitalista, das trocas de mercado". ${ }^{15}$ Os referenciais identificantes socioculturais (como simbologia, tradição, linguagem específica, etc.), que as sociedades costumam criar para gerar reconhecimento entre os seus membros, estão sendo cada vez mais substituídos por referenciais identificantes eminentemente comerciais (dotados de uma linguagem universal: the language of business) e teleologicamente centrados na manutenção da própria lógica do mercado. Se reificação representa perda de reconhecimento, estamos então dentro de um contexto no qual o diálogo, a troca de ideias - não apenas troca de mercadorias ou bens negociáveis - e o derradeiro acordo se tornam práticas quase impossíveis - improváveis, no mínimo - de se realizar longe da intervenção de um terceiro imparcial.

Quanto ao fenômeno da judicialização das relações sociais, a referida perda dos sentimentos de comunidade, reconhecimento e identidade, já se constitui em uma possível causa. Todavia, a judicialização da política tem um significado bem mais específico e concreto, representando, normalmente: (1) a expansão do poder dos juízes e a consequente transferência do poder de criação normativa, característico do Legislativo, para o Judiciário; e (2) a criação de métodos e técnicas decisórias fora daquilo que habitualmente tem sido utilizado. ${ }^{16}$

A questão concernente aos métodos e técnicas decisórias utilizados para além do que a técnica judicial costuma produzir será analisada com maior atenção nas próximas sessões.

\section{Política e Direito: Bens distintos, Racionalidades distintas}

Quando observamos prima facie a temática atinente ao ativismo judicial, uma das primeiras questões que costuma saltar aos olhos é uma possível ofensa ao princípio da separação dos poderes. Muitos críticos procuram se centrar nesse argumento para tentar retirar a legitimidade do fenômeno em questão, sustentando que ele seria por 
si só ilegítimo e inconstitucional. ${ }^{17}$ Entretanto, o problema vai muito além de uma ofensa ao princípio constitucional da separação de Poderes: estamos diante de uma confusão conceitual e funcional entre Direito e Política. O ativismo judicial é apenas um dos sintomas mais flagrantes de que as sociedades de massa da era pós-moderna não se satisfazem mais com as prestações de serviços públicos e tutela de direitos individuais ainda nos moldes do Estado moderno; este se revela incapaz de lidar com as necessidades e demandas que crescem em um ritmo frenético no seio da sua própria população. A Política encontra-se acometida pela burocracia - e progressiva burocratização - do Estado, pela insuficiência regulatória, pelo descompasso frente à realidade social e pelo déficit de legitimidade que as democracias ocidentais apresentam quando comparadas com os ideais sociais e expectativas populares que suas respectivas sociedades projetam. Mais do que uma discussão acerca da separação dos poderes, o ativismo judicial nos propõe uma discussão acerca do que atualmente representam os limites entre Direito e Política.

Diante desse cenário, o magistrado, em todas as instâncias jurisdicionais, é chamado a atender demandas cujo elevado e crescente grau de complexização impede que ele se mantenha adstrito ao padrão de racionalidade jurídica, bem como às técnicas hermenêuticas e decisórias, que fundamentavam a era do apogeu do positivismo jurídico ocidental, durante o século XIX e a primeira metade do XX. Com isso, elementos tradicionais foram alterados nas suas concepções mais fundamentais, outros surgiram e se consolidaram, mas o resultado circunstancial desse processo social de modificação de categorias elementares do Direito e da Política culmina em uma nova ideia de racionalidade jurídica.

A primeira grande concepção foi alterada, no pós- $2^{a}$ Guerra Mundial, de modo decisivo: o conceito de norma jurídica.

Até o século XIX se costumava distinguir os princípios e as normas jurídicas como categorias jurídicas de esferas diferentes e autônomas. Ambos faziam parte do mundo jurídico, mas eram considerados espécies diferentes. Às normas jurídicas competia a tarefa disciplinadora, ou seja, normativa, restando aos princípios um campo de atuação cuja normatividade era muito restrita, ou inexistente, quando comparado ao das normas jurídicas. Uma modificação conceitual de extrema significância ocorreu quando a norma jurídica passou a ser compreendida como gênero dentro do qual residem os princípios e as regras. Ou seja, criaram-se as subcategorias "norma-princípio" e "norma-regra".

A questão da normatividade dos princípios é bem tratada por Robert Alexy quando ele afirma:

Tanto las reglas como los principios son normas porque ambos dicen lo que debe ser. Ambos pueden ser formulados con la ayuda de las expressiones deónticas básicas del mandato, la permisión y la prohibición. Los principios, al igual que las reglas, son 
razones para juicios concretos de deber ser, aun cuando sean razones de un tipo muy diferente. La distinción entre regras y principios es pues una distinción entre dos tipos de normas. ${ }^{18}$

Sob diversas perspectivas, podemos fazer a distinção entre princípios e regras, mas o critério de generalidade sempre é o mais frequente. ${ }^{19}$ Segundo tal referência, os princípios são normas de grau de generalização mais alto do que o das regras, pois estas possuem uma situação fática a ser disciplinada já bem determinada ou a qual pode ser facilmente determinável. Enquanto isso, os princípios não encontram uma situação fática determinada com igual precisão, aplicando-se a um conjunto de situações variáveis. Veja-se, por exemplo, que uma regra que estabelece requisitos para um contrato comercial possui baixa generalização e alta concretude, pois sabemos objetivamente o que fazer para celebrar um contrato comercial válido. Todavia, se pensamos no princípio da boa-fé processual, dar-se-á uma inversão: estamos diante de uma norma de alta generalização e baixa concretude. Como se não bastasse a área de aplicação do referido princípio possuir um elevado grau de abstração, percebemos que até mesmo para alcançar uma definição pacífica de "boa-fé" - mesmo no plano semântico e epistemológico - , já será difícil. Age com boa-fé processual alguém que sempre recorre de decisões cujo mérito já se encontra assentado no Tribunal em sentido oposto aos seus interesses? Age com boa-fé aquela parte que pede assistência judiciária gratuita, ainda que não se enquadre nos requisitos legais e esteja apenas na expectativa de uma desatenção ou tolerância do magistrado? A abstração da norma-princípio em tela não nos permite uma resposta tão precisa e pacífica quanto aquela que seria dada a alguém que desejasse saber os requisitos legais de um contrato de constituição de sociedade anônima, por exemplo.

Para auxiliar a distinção entre princípios e regras, J. J. Gomes Canotilho sintetiza alguns critérios que permitem visualizar a natureza normativa de ambos e delimitar os seus âmbitos de aplicação:

a) Grau de obstracção: os princípios são normas com um grau de abstracção relativamente elevado; de modo diverso, as regras possuem uma abstracção relativamente reduzida.

b) Grau de determinabilidade na aplicação do caso concreto: os princípios, por serem vagos e indeterminados, carecem de mediações concretizadoras (do legislador? do juiz?), enquanto as regras são suscetíveis de aplicação direta.

c) Carácter de fundamentalidade no sistema das fontes de direito: os princípios são normas de natureza ou com um papel fundamental no ordenamento jurídico devido à sua posição hierárquica no sistema das fontes (p.ex.: princípios 
constitucionais) ou à sua importância estruturante dentro do sistema jurídico (p.ex.: princípio do Estado de Direito).

d) "Proximidade" da ideia de direito: os princípios são “standards" juridicamente vinculantes radicados nas exigências de "justiça” (Dworkin) ou na "ideia de direito" (Larenz); as regras podem ser normas vinculativas com um conteúdo meramente funcional.

e) Natureza normogenética: os princípios são fundamento de regras, isto é, são normas que estão na base ou constituem a ratio de regras jurídicas, desempenhando, por isso, uma função normogenética fundamentante. 20

Por se consubstanciarem em normas dotadas de maior abrangência, os princípios servem de conteúdo e sentido às normas constitucionais singularmente consideradas ou aos sistemas constitucionais dos diversos Estados, uma vez que representam as pautas axiológicas de uma sociedade política em um determinado momento de seu processo histórico. Devem ser considerados como princípios de um ordenamento jurídico todas aquelas orientações e determinações de caráter geral e fundamental que se possam inferir da estrutura sistemática, da coordenação hierárquica e da racionalidade jurídica presente em todo o sistema normativo.

Entretanto, cabe ainda mencionar que os princípios jurídicos não se identificam com valores, na medida em que estes não determinam o que deve ser, mas sim o que é melhor. Da mesma forma, no caso de uma colisão entre valores, a solução não determina o que é devido, apenas indica o que é melhor. Em vez de possuir o caráter deontológico dos princípios, os valores possuem somente o axiológico. Ademais, os princípios jurídicos não se confundem com o mero estabelecimento de fins, visto que os fins apenas indicam um estado almejado ou uma decisão sobre a realização desse estado desejado, sem que seja estabelecido um dever-ser. O estabelecimento de fins, quando motivados por meio de um dever-ser, passa a constituir um princípio.

Ressalte-se, também, que os princípios jurídicos não se confundem com axiomas. ${ }^{21}$ Pode-se definir axioma como uma proposição cuja veracidade é aceita por todos, de forma unânime, de tal modo que não é nem possível, nem necessário provála. Assim, os axiomas são aplicáveis tão somente por meio da lógica, sendo deduzidos sem a intervenção de pontos de vista materiais. A característica de ser autoevidente faz com que a veracidade de um axioma seja demonstrada pela sua própria e mera afirmação. Um axioma deve ser entendido como um "bem", ou melhor, um "ser-em-si", mas nunca como um “dever-ser”, pois esta é a função da norma jurídica, seja ela norma-regra ou norma-princípio.

O italiano Riccardo Guastini define princípios como normas providas de um alto grau de generalidade, de um alto grau de indeterminação e, por isso, requerem 
concretização por via interpretativa, sem a qual não seriam suscetíveis de aplicação a casos concretos. ${ }^{22}$ A necessidade de concretização por via interpretativa é o ponto chave que devemos considerar para determinar uma das mais significativas modificações na racionalidade jurídica empregada pelo intérprete/aplicador no momento de decidir uma controvérsia. Caíram por terra os mitos exegéticos de um "legislador racional" capaz de antever todas as situações possíveis para o emprego da norma jurídica, de modo que restava ao intérprete tão somente aplicar a lei por subsunção ${ }^{23}$ ao caso concreto. Durante o século XIX e grande parte do século XX, a racionalidade jurídica ficou limitada ao raciocínio subsuntivo: a tarefa do intérprete, ou melhor, do juiz, era restrita a encontrar a norma do caso concreto e a ele aplicar. ${ }^{24}$ O Código Civil francês (Códe Napoléon) de 1803 reforçou decisivamente, por um lado, o mito em torno de um legislador onipotente, onisciente e onipresente, capaz de fazer normas desprovidas de lacunas e capazes de durar por toda a eternidade, enquanto, por outro lado, afirmava a técnica da subsunção como padrão de racionalidade jurídica a ser seguido. ${ }^{25}$

Ressalte-se que continuamos a pensar, primordialmente, por subsunção, pois esta é a primeira forma de enquadrar o fenômeno real ao plano normativo. Quando estamos diante de, por exemplo, um delito de estupro (premissa menor: " $\mathrm{X}$ ' foi estuprada”), imediatamente pensaremos no tipo penal correspondente (premissa maior: "Código Penal. Art. 213. Constranger alguém, mediante violência ou grave ameaça, a ter conjunção carnal ou a praticar ou permitir que com ele se pratique outro ato libidinoso. Pena: reclusão, de 6 (seis) a 10 (dez) anos"), de modo que a síntese dessa subsunção demandará aplicação de alguma pena. Se "X" não tiver sido estuprada, não se dará a subsunção. Isso é a lógica do "tudo ou nada”, de que fala Dworkin, característica das regras. ${ }^{26}$ No entanto, somente os “casos fáceis” são decididos com base em regras, cabendo aos princípios servir de fonte para que se possa decidir sobre os "casos difíceis", isto é, encontrar soluções jurídicas para situações fáticas que não encontram a devida previsão legal ou regulamentação em condições de atender as exigências regulativas do caso concreto.

Subsidiariamente à subsunção, diversas técnicas hermenêuticas foram surgindo para tentar atender a tais exigências, criando inclusive técnicas específicas de acordo com a matéria envolvida, como é o caso da hermenêutica constitucional. ${ }^{27} \mathrm{O}$ caráter abstrato e o elevado grau de generalidade dos princípios, sobretudo dos princípios constitucionais, permitem que o julgador possa decidir tão somente com base em princípios e, até mesmo, contra legem, mas desde que esteja sustentado em uma fundamentação principiológica apta a desconstituir a validade, legitimidade ou necessidade premente de aplicação de determinada norma-regra, sobretudo em condições de deslegitimar a fundamentação principiológica desta. São incontáveis os casos de regras que são excetuadas pela jurisdição ordinária para que pudesse prevalecer algum princípio constitucional que assegura direito fundamental, tanto que vamos nos abster de exemplificações. 
Aqui vemos então um primeiro elemento a determinar o que caracteriza a racionalidade jurídica do ativismo judicial: decisões fundamentadas substancialmente em princípios, afastando ou negando a aplicabilidade de regras específicas para a fatispécie. Se Schlesinger, no seu texto famoso de 1947, não se manifestou sobre ser o ativismo judicial algo positivo ou demeritório, parece não haver dúvidas de que os direitos fundamentais devem preponderar, como regra geral, frente a demais normas do ordenamento jurídico, mesmo outras de natureza constitucional.

Desse modo, vamos denominar aqui ativismo judicial positivo aquele que se enquadra no padrão de racionalidade jurídica vigente no ordenamento em questão e busca, em última instância, assegurar direitos fundamentais ou garantir a supremacia da Constituição, enquanto denominaremos nociva toda prática ativista que fuja desse quadro ou busque, sobretudo, fazer preponderar um padrão de racionalidade eminentemente político. ${ }^{28}$

$\mathrm{Na}$ tentativa de sintetizar as principais modalidades de ativismo judicial, Kmiec apresenta o seguinte rol, que consideraremos aqui como práticas nocivas (exceto o item 4, à estabilidade interinstitucional e ao ordenamento constitucional:

1. Invalidar ou afastar a aplicabilidade de atos oriundos de outros Poderes. ${ }^{29}$ Ocorre quando a decisão judicial considera nulo ou inaplicável ato do Legislativo ou do Executivo, mesmo sendo o ato em questão constitucional. Conforme já referimos anteriormente, judicial activism e judicial review não se confundem, pois neste existe um controle de legitimidade constitucional de atos normativos ou com força de lei, enquanto naquele a decisão se baseia em argumentos políticos, como, por exemplo, o fato de uma dada lei ter sido aprovada por liberais.

2. Afastar a aplicação de precedentes. ${ }^{30} \mathrm{Em}$ sistemas de Common Law a força do precedente decorre do respeito ao princípio do stare decisis, ${ }^{31}$ o que importa dizer que um caso análogo já julgado somente não será aplicado a um caso futuro quando não ocorrer identidade entre os elementos que caracterizam ambos os casos, ou então quando for necessário uma inovação jurisprudencial, em virtude de princípios ou novas regras que demandam aplicação. O ativismo judicial pode deixar de afastar precedentes verticais, vindos de instâncias superiores ou inferiores, bem como precedentes horizontais. Esse último caso se mostra mais gravoso, uma vez que um entendimento consolidado pela própria Corte está deixando de ser aplicado a um caso que demandaria a sua aplicação. É o que ocorreu no recente Citizens United v. Federal Election Commission, julgado em janeiro de 2010, pela Suprema Corte dos Estados Unidos, onde "Os cinco juízes conservadores, por sua própria iniciativa, sem qualquer pedido das partes no processo, declararam que as corporações e os sindicatos têm o direito constitucional de gastar tanto quanto desejarem em 
comerciais de televisão especificamente eleitoral ou visando a apoiar determinados candidatos". ${ }^{32}$ Ainda que tenha chamado mais a atenção por diversos outros motivos, a racionalidade empregada na decisão foi notadamente política: objetivou permitir que setores da política estadunidense pudessem explorar, ilimitadamente, a mídia televisiva durante as eleições de 2010.

3. Atuar como legislador. ${ }^{33}$ Mesmo tendo a legitimidade para atuar apenas como "legislador negativo", isto é, para remover do ordenamento jurídico normas inconstitucionais, outra prática nocisiva é a de proferir decisões que se constituem em verdadeiras criações legislativas, pois vão além das competências jurisdicionais, costumam ser extra petita, geram instabilidade institucional e culminam na produção de insegurança jurídica. Trata-se de algo por completo diverso de uma inovação jurisprudencial: o fundamento decisório está na própria decisão ou em uma interpretação torpe de legislação não aplicável ao caso, como, por exemplo, mediante analogia entre casos que não possuem a mínima identidade entre si.

4. Utilização de técnicas hermenêuticas reconhecidas pela doutrina. ${ }^{34}$ Trata-se de uma situação intermediária entre o uso nocivo do ativismo judicial e o uso positivo. A diversidade de técnicas interpretativas e decisórias atribui ao julgador uma ampla gama de possibilidades para produzir a decisão. Todavia, o fato de estar prevista na doutrina não significa que já esteja sendo jurisprudencialmente empregada, o que pode dar ensejo a uma prática ativista nociva, quando não estiver vinculada à efetividade de direitos fundamentais ou supremacia da Constituição.

5. Julgamentos predeterminados a fins específicos. ${ }^{35}$ Essa é a modalidade mais nociva de ativismo judicial: atender a um fim específico, mesmo que para tanto seja necessário uma decisão contra legem ou extra petita. Não podemos confudir essa situação com as naturais orientações morais, ideológicas e políticas que cada um de nós possui e influenciam o modo como interpretamos os fatos, o mesmo valendo para como os magistrados julgam, obviamente. Porém, ser influenciado por orientações pessoais de natureza diversa não significa estar orientado a determinado fim: a pretederminação remete ao decisionismo político, algo que merece maiores considerações.

Do ponto de vista estrutural, se a racionalidade jurídica possui um quadro normativo determinado dentro do qual está orientada à realização dos bens tutelados pelo ordenamento jurídico, o mesmo não ocorre com a racionalidade política: esta encontra diversos setores da sociedade que possuem bens próprios, frequentemente conflitantes com os bens de outros setores concorrentes, e dependem da escolha 
política para fazer valer seus interesses. A decisão política não considera tão somente o bem-em-si e a sua necessidade de tutela, mas avalia os seus impactos sociais, interessados na sua proteção ou garantia, e a vinculação desse bem ao setor da sociedade que dá legitimidade a quem tem o poder de decidir.

De outra sorte, do ponto de vista subjetivo (hermenêutico), aquele que exerce o poder decisional encontra-se vinculado pela axiologia específica do setor, ou setores, responsáveis pela sua legitimidade. Os bens e interesses dos demais setores serão considerados não mais do que secundariamente, recebendo tutela somente quando satisfeitos os daqueles que lhe deram legitimidade. A concepção aristotélica de bem comum, a ser garantido na polis (cidade-Estado) por meio da Política, pressupunha uniformidade cultural, unidade ética e baixíssima complexização social. Nas atuais sociedades ocidentais de altíssima e crescente complexização social, multiculturais e fragmentadas em diversos microssistemas éticos, o bem comum se encontra cada vez mais reduzido, não indo muito além do que a busca da estabilidade do próprio macrossistema social. Os setores sociais construíram suas próprias axiologias, de modo que aquele que assume o poder decisional estará, inexoravelmente, vinculado aos valores e aos interesses daqueles responsáveis pela sua ascenção ao poder. Por exemplo, uma liderança política legitimada pela classe operária não considerará em, primeiro plano, os bens e interesses da classe patronal, e vice-versa.

Diante disso, a forma mais nociva de ativismo judicial é aquela que vincula o julgador a um setor ou setores sociais específicos, em detrimento de indivíduos cujos interesses se encontram juridicamente protegidos, os quais teriam no Judiciário o espaço derradeiro para a sua proteção. Não se confunda essa prática com julgar influenciado por orientações pessoais, pois, conforme já falamos, qualquer indivíduo possui preferências políticas, religiosas e morais (bem como sexuais, gastronômicas, enológicas, etc.), mas isso não impede que a decisão esteja em plena conformidade com o ordenamento jurídico vigente. Isso parece algo pacífico e sem maiores complicações. A nocividade maior do ativismo judicial ocorre quando a decisão judicial tem um fim político e depende da negação à tutela de interesses legítimos de alguma parte da ação, fundamentando-se em argumentos que transcendem a racionalidade jurídica - veja-se o ilustrativo caso da Suprema Corte dos EUA, Citizens United v. Federal Election Commission, 130 S. Ct. 876 (2010), suprarreferido.

\section{Quais são as Perspectivas PARA O ATIVISMO JUDicial No BRASil?}

Se nos EUA o ativismo judicial possui longa data e continua gerando polêmica, no Brasil esse fenômeno é relativamente recente e ainda deverá ter ulteriores desenvolvimentos.

Um juiz ativista, em sentido positivo, atua na busca da proteção dos direitos fundamentais e da garantia da supremacia da Constituição, assumindo uma postura concretizadora quando diante da abstração de princípios constitucionais, como 
dignidade da pessoa humana, proteção ao menor, assistência aos desamparados, etc. A realização da Constituição passa pela atividade intelectual de interpretar/aplicar conceitos e categorias jurídicas de elevado grau de generalidade e abstração, mesmo que para tanto seja necessário abraçar competências institucionais que ordinariamente tocam a outros Poderes. O problema com essa sorte de postura seria estarmos substituindo a vontade do soberano que criou a lei e a Constituição pela vontade do intérprete. ${ }^{36}$

No entanto, a omissão, seja administrativa ou legislativa, do gestor público ou do legislador frente ao dever de dar efetividade à Constituição não pode ser corroborada pela omissão também do Judiciário frente a tal dever. Não se fala aqui em ativismo judicial nocivo, no qual o juiz ultrapassa os limites entre racionalidade jurídica e racionalidade política, valendo-se somente dessa última. Intepretar limitado pela mens legis (sentido da lei) e pela mens legislatoris (vontade do legislador) não impede que ao juiz seja necessário fazer uma construção hermenêutica para poder solucionar o caso concreto. A norma jurídica conterá, inevitavelmente, um espaço jurídico "vazio" a ser preenchido pelo intérprete/aplicador, isto é, uma situação real que demanda a aplicação da norma, mas esta não prescreve o modo como isto se dará. Mesmo para Kelsen, o mais notório expoente do positivismo jurídico do século XX, a norma jurídica representava uma moldura que deveria ser preenchida durante o processo hermenêutico, pois continha diversos espaços em branco. ${ }^{37}$ Falamos aqui em ativismo judicial como atuação contra as omissões dos demais Poderes.

Destacando a necessidade de enfrentar tais omissões, o ministro Celso de Mello sustentou que:

Nem se censure eventual ativismo judicial exercido por esta Suprema Corte, especialmente porque, dentre as inúmeras causas que justificam esse comportamento afirmativo do Poder Judiciário, de que resulta uma positiva criação jurisprudencial do direito, inclui-se a necessidade de fazer prevalecer a primazia da Constituição da República, muitas vezes transgredida e desrespeitada por pura, simples e conveniente omissão dos poderes públicos. ${ }^{38}$

No mesmo sentido, seguiu afirmando que:

Práticas de ativismo judicial, Senhor Presidente, embora moderadamente desempenhadas por esta Corte em momentos excepcionais, tornam-se uma necessidade institucional, quando os órgãos do Poder Público se omitem ou retardam, excessivamente, o cumprimento de obrigações a que estão sujeitos por expressa determinação do próprio estatuto constitucional, ainda mais se se tiver presente que o Poder Judiciário, tratando-se de comportamentos estatais ofensivos à Constituição, não pode se reduzir a uma posição de pura passividade. ${ }^{39}$ 
$\mathrm{O}$ ato de decidir não pode estar limitado a dar uma resposta ao caso concreto. $\mathrm{O}$ julgador orientado pela mera necessidade de responder acaba se afastando da necessidade de julgar, isto é, da necessidade de ponderar os principais elementos que compõem o caso concreto; de considerar também as omissões dos demais Poderes pelas quais as partes já foram submetidas; de analisar, enfim, os impactos que a sua decisão produzirá na realidade material e como ela terminará se constituindo, ou não, em um instrumento de proteção dos direitos fundamentais e de garantia da supremacia da Constituição.

Em um cenário político-institucional de elevada burocratização, de progressiva judicialização das relações sociais e de crescente distanciamento da relação entre Estado e indivíduo, o ativismo judicial positivo corrobora, em caráter de exceção, para a realização dos fins e objetivos estabelecidos pela Constituição. As técnicas hermenêuticas possuem grande desenvolvimento em sólo pátrio para poder oferecer elementos precisos na determinação de condutas judiciais ativistas positivas ou nocivas, de modo que seja possível exercer um controle já dentro do próprio Judiciário em relação aos eventuais excessos. Embora o Estado não apresente estruturas eficazes de mediação dos conflitos sociais de modo extrajudicial, ele mesmo se vale do Judiciário como forma de se fazer presente na realidade social e de reafirmar a sua legimidade como agente responsável pela promoção da paz social.

De outra sorte, se as omissões do Executivo e do Legislativo legitimam o Judiciário a intervir na tutela dos direitos fundamentais, não podemos esquecer que a legitimidade política do Judiciário em si impede que ele se torne o regular promotor dos objetivos fundamentais da República brasileira. Por um lado, na jurisdição ordinária, os juízes são selecionados mediante concurso público, sem qualquer participação popular na escolha, enquanto no âmbito dos tribunais superiores, sobretudo no caso do Supremo Tribunal Federal, os nomes dos magistrados são escolhidos pelo chefe do Executivo, inexistindo também a mínima participação popular nesse processo. O déficit democrático do Judiciário no enfrentamento dos assuntos de maior gravidade enfraquece a legitimidade do Estado como agente de promoção da paz social e do desenvolvimento humano, pois as escolhas políticas fundamentais, quando feitas pelo Judiciário, não possuem a representatividade popular necessária e, em consequência, não podem ser cobradas pelo próprio povo, como ocorre, por exemplo, com o "julgamento pelas urnas" ao qual os membros de cargos eletivos do Executivo e do Legislativo são submetidos, no mínimo, a cada quatro anos. ${ }^{40}$

\section{CONSIDERAÇÕES FINAIS}

Nocivo ou não, o ativismo judicial representa a insuficiência do Estado em atender aos anseios da sua população, bem como em buscar a realização dos objetivos que lhe foram postos: trata-se de uma patologia constitucional. Uma conduta que deveria ser a 
exceção à regra converte-se em forma ordinária de composição dos mais diversos conflitos sociais, transformando o Judiciário em "esfera pública” de decisão tanto das questões mais fundamentais para o Estado e para a sociedade quanto de situações banais do cotidiano. ${ }^{41}$

Em síntese, podemos afirmar que quatro são as espécies de condutas ativistas que mais lesam o equilíbrio da ordem constitucional e da estabilidade interinstitucional:

1. Atuação como legislador positivo: é a forma mais flagrante de ativismo judicial nocivo, pois decorre de comportamento do Judiciário que tem por fim extrapolar sua condição de imparcialidade e produzir construções normativas incompatíveis até mesmo com o que as modernas técnicas hermenêuticas oferecem em termos de preenchimento de lacunas jurídicas e de resolução de conflitos entre normas.

2. Ofensa ao princípio da separação dos Poderes: ocorre quando o Judiciário vai além das suas prerrogativas funcionais e toma para si competências que são atinentes a outros Poderes. Embora seja uma modalidade sutil de ativismo judicial, uma vez que a quase totalidade das matérias que competem aos Poderes Públicos pode em algum momento ser objeto de exame pelo Judiciário, a conduta deste encontra limites que devem ser respeitados e muitas vezes estão postos pela própria natureza da causa em julgamento.

3. Desconsideração por precedentes jurisprudenciais: ocorre quando, sobretudo em se tratando de precedentes do mesmo Tribunal, a decisão desconsidera ou colide com entendimentos consolidados em jurisprudência firmada sobre matéria análoga ou idêntica, sem que, para tanto, tenha ocorrido alguma circunstância nova a ensejar mudança de orientação jurisprudencial. Trata-se também de espécie de ativismo judicial nocivo difícil de ser caracterizada, pois as decisões judiciais são o espaço adequado para que inovações possam surgir, mas tais inovações não podem carecer de sólida fundamentação normativa (não apenas legal) e adequação às exigências do caso concreto.

4. Decisões judiciais viciadas por decisionismo político: já expomos que essa é a modalidade mais nociva de ativismo judicial, pois, antes mesmo de se conhecer os pormenores do caso concreto, parte-se de predeterminações e predefinições que fogem dos limites da causa e buscam a satisfação de orientações morais, ideológicas ou políticas que o julgador possui. Ou seja, ocorre quando se busca encontrar qualquer fundamento legal ou jurisprudencial, por mais incompatível que seja com as exigências regulativas do caso concreto, apenas para justificar a adoção de uma decisão já predefinida ideologicamente. ${ }^{42}$ 
Quanto a uma possível definição de ativismo judicial positivo, entendemos que a sua caracterização ocorre com a existência de algum dos seguintes elementos (já analisados anteriormente):

1. Decisão que busque primordialmente assegurar direitos fundamentais;

2. Decisão orientada à garantia da supremacia da Constituição;

3. Decisão fundamentada substancialmente em princípios jurídicos, sobretudo em princípios constitucionais;

4. Decisão sustentada por técnicas hermenêuticas que não extrapolem a mens legis e não derroguem a mens legislatoris do ato normativo em questão.

Mais importante do que estabelecer uma definição conceitual dogmaticamente precisa de ativismo judicial ou então bradar contra toda e qualquer espécie sua, devemos reconhecer que se trata de uma patologia constitucional cada vez mais necessária - desde que seja na sua vertente positiva - , para a proteção do indivíduo contra omissões ou excessos do Estado. Hipoteticamente, a partir de um critério de negação, o que ocorreria se também o Judiciário decidisse abandonar uma postura ativista e passasse a se omitir diante das ofensas aos direitos fundamentais que muitas vezes são perpetradas pelo próprio Estado? A quem restaria recorrer?

: ARTIGO APROVADO (01/06/2012) : RECEBIDO EM 21/07/2011

NOTAS

Este artigo originou-se em pesquisas desenvolvidas durante estágio pós-doutoral na Universidade de Florença, Itália, em 2010, sob a supervisão do Prof. Maurizio Fioravanti.

1 "I had to invent a mythical judge, called Hercules, with superhuman powers in order even to contemplate what a full justification of the entire system would be like. Real judges can attempt only what we might call a partial justification of the law. They can try to justify, under some set of principles, those parts of the legal background which seem to them immediately relevant, like, for example, the prior judicial decisions about recovery for various sorts of damage in automobile accidents. Nevertheless it is useful to describe this as a partial justification - as a part of what Hercules himself would do - in order to emphasize that, according to this picture, a judge should regard the law he mines and studies as embedded in a much larger system, so that it is always relevant for him to expand his investigation by asking whether the conclusions he reaches are consistent 
with what he would have discovered had his study been wider." Ronald Dworkin, Natural Law Revisited (University of Florida Law Review, v. 34, 1982, p.165).

2 Ver os clássicos Sadok Belaid, Essai sur le Pouvoir Créateur et Normatif du Juge (Paris: Librairie Générale de Droit et de Jurisprudence, 1974); e Mauro Cappelletti, Juízes legisladores? (Porto Alegre: SAFE, 1999).

3198 US 45 (1905).

4 "Section 110 of the labor law of the State of New York, providing that no employes shall be required or permitted to work in bakeries more than sixty hours in a week, or ten hours a day, is not a legitimate exercise of the police power of the State, but an unreasonable, unnecessary and arbitrary interference with the right and liberty of the individual to contract in relation to labor, and, as such, it is in conflict with, and void under, the Federal Constitution.” Lochner v. People of New York, 198 US 45 (1905).

5 Sobre a Era Lochner, Cass Sunstein afirma que: "The received wisdom is that Lochner was wrong because it involved 'judicial activism': an illegitimate intrusion by the courts into a realm properly reserved to the political branches of government. This view has spawned an enormous literature and takes various forms. The basic understanding has been endorsed by the Court in many cases taking the lesson of the Lochner period to be the need for judicial deference to legislative enactments". Cass R. Sustein, Lochner's Legacy, Columbia Law Review, v. 87, n. 5, 1987, p. 874.

6 Keenan D. Kmiec, The Origin and Current Meaning of "Judicial Activism", California Law Review, v. 92, n. 5, 2004, p. 1446 .

7 Idem, ibidem.

8 Idem, ibidem, p. 1447.

9 Keenan D Kmiec, op. cit., p. 1463-1476.

10 Ver o posicionamento crítico (talvez demasiadamente crítico) de Robert M. Cover, The Origins of Judicial Activism in the Protection of Minorities, The Yale Law Journal, v. 91, 1982, p. 1287-1316.

11 Para um estudo sobre o surgimento da affirmative action, ver Mark R. Killenbeck, Pushing Things up to Their First Principles: Reflections on the Values of Affirmative Action (California Law Review, v. 87, n. 6, 1999, p. 1299-1407); John Cocchi Day, Retelling the Story of Affirmative Action: Reflections on a Decade of Federal Jurisprudence in the Public Workplace, (California Law Review, v. 89, n. 1, 2001, p. 59-127); e ainda Joaquim Barbosa Gomes, Ação Afirmativa \& Princípio Constitucional da Igualdade. A Experiência dos EUA (Rio de Janeiro: Renovar, 2001).

12 Cf. Michele MOSES, Affirmative Action and the Creation of More Favorable Contexts of Choice, American Educational Research Journal, v. 38, n. 1, 2001, p. 05-06.

13 A Emenda Constitucional n. 16/65 alterou o art. 101 da Constituição de 1946, dispondo da seguinte forma: "Art. 2 - As alíneas $c, f, i$ e $k$, passam a ter a seguinte redação: (...) k) a representação contra inconstitucionalidade de lei ou ato de natureza normativa, federal ou estadual, encaminhada pelo ProcuradorGeral da República". Registre-se que a alínea "k" do art. 101 é onde estão definidas as competências do Supremo Tribunal Federal.

14 Cf. Axel Honneth, La Réification. Petit Traité de Théorie Critique (Paris: Gallimard, 2007, p. 82).

15 Idem, ibidem, p. 107.

16 Cf. Torbjörn Vallinder, The Judicialization of Politics - A Word-wide Phenomenon: Introduction, International Political Science Review, v. 15, n. 2, 1994, p. 91.

17 Elival da Silva Ramos sustenta que "por ativismo judicial deve-se entender o exercício da função jurisdicional para além dos limites impostos pelo próprio ordenamento que incumbe, institucionalmente, ao Poder 
Judiciário fazer atuar, resolvendo litígios de feições subjetivas (conflitos de interesse) e controvérsias jurídicas de natureza objetiva (conflitos normativos). Há, como visto, uma sinalização claramente negativa no tocante à práticas ativistas, por importarem na desnaturação da atividade típica do Poder Judiciário, em detrimento dos demais Poderes", Elival da Silva Ramos, Ativismo judicial: parâmetros dogmáticos (São Paulo: Saraiva, 2010, p. 129).

18 Robert Alexy, Teoria de los Derechos Fondamentales (Madrid: Centro de Estudos Constitucionales, 1997, p. 83).

19 "Por princípios fundamentais entendem-se, por ora, os critérios ou as diretrizes basilares do sistema jurídico, que se traduzem como disposições hierarquicamente superiores, do ponto de vista axiológico, às normas estritas (regras) a despeito da aparência de mais genéricos e indeterminados. São linhas mestras de acordo com as quais guiar-se-á o intérprete quando se defrontar com as antinomias jurídicas.

De sorte que, consubstanciada a colisão, deve ser realizada uma interpretação em conformidade com os princípios (dotados de fundamentalidade). A primazia da 'fundamentalidade' faz com que - seja na colisão de princípios, seja na colisão de regras - um princípio, não uma regra, venha a ser erigido como preponderante, como será visto. Jamais haverá conflito de regras que não se mostre solúvel à luz de princípios fundamentais, apesar de esse processo não se fazer translúcido para boa parte dos observadores”, Juarez Freitas, Interpretação Sistemática do Direito, p. 58.

20 José Joaquim Gomes Canotilho, Direito Constitucional, 6. ed. (Coimbra: Livraria Almedina, 1993, p. 166-167).

21 Alexy coloca a distinção nos seguintes termos: "La diferencia entre principios y valores se reduce así a un punto. Lo que en el modelo de los valores es prima facie lo mejor es, en el modelo de los principios, prima facie debido; y lo que en el modelo de los valores es definitivamente lo mejor es, en el modelo de los principios, definitivamente debido. Así pues, los principios y los valores se diferencian sólo en virtud de su carácter deontológico y axiológico respectivamente", Robert Alexy, Teoria de Los Derechos (p. 147).

22 Riccardo Guastini, Distinguendo: Studi di Teoria e Metateoria del Diritto (Torino: Giappichelli, 1996, p. 57).

23 “Em nossa linguagem, existem, além dos conectivos lógicos e os quantificadores, dois tipos de termos e sintagmas dotados de referência semântica: por um lado, os nomes próprios e, com eles, as descrições definidas (Hans Kelsen, a Suprema Corte, o assassino de Lincoln, o contrato entre Tim e Tom, etc.) que se referem a sujeitos, fenômenos, eventos individuais; por outro lado, os predicados (jurista, juiz, homicídio, contrato, etc.) que denotam classes (a classe dos juristas, a classe dos juízes, etc.). Portanto, subsumir significa enquadrar um indivíduo (em sentido lógico) numa classe (subsunção individual) ou, ainda, incluir uma classe numa outra mais ampla (subsunção genérica). Em outras palavras, subsumir significa, banalmente, usar um conceito. A locação é um contrato que inclui a classe das locações na mais ampla classe dos contratos ou, ainda, aplica à locação o conceito de contrato. Tício é cidadão americano inclui o indivíduo Tício na classe dos cidadãos americanos, ou seja, aplica o conceito de cidadão americano a Tício ou, ainda, caso se queira, usa o conceito de cidadão americano para qualificar Tício. Isso, e nada mais, é a subsunção", Riccardo Guastini, Os princípios constitucionais como fonte de perplexidade, in: Anderson V. Teixeira; Elton S. Oliveira, orgs., Correntes contemporâneas do pensamento jurídico (Barueri: Manole, 2009, p. 52).

24 “O argumento fundamental que guia os operadores do direito no seu raciocínio jurídico é o princípio da autoridade, isto é, a vontade do legislador que pôs a norma jurídica; pois bem, com a codificação, a vontade do legislador é expressa de modo seguro e completo e aos operadores do direito basta ater-se ao ditado pela autoridade soberana”, Norberto Bobbio, O positivismo jurídico (São Paulo: Ícone, 1999, p. 78-79).

25 Parafraseando Lucien Jaume, o italiano Gustavo Zagrebelsky refere que o período pós-Code Civil poderia ser denominado Légicentrisme, pois a atuação dos juízes e dos tribunais deveria se limitar a de mero aplicador das normas promulgadas pelo Legislativo, não cabendo juízo de ponderação ou relativização em relação a elas. Cf. Gustavo Zagrebelsky, La Legge e la sua Giustizia (Bologna: Il Mulino, 2008, p. 114-115) e em Il Diritto Mite (Torino: Einaudi, 1992, p. 66).

26 "Rules are applicable in an all-or-nothing fashion. If the facts a rule stipulates are given, then either the rule is valid, in which case the answer it supplies must be accepted, or it is not, in which case it contributes nothing to the decision”, Ronald Dworkin, Taking Rights Seriously (Londres: Duckworth, 1978, p. 24). 
27 Para ulteriores estudos sobre a hermenêutica constitucional, recomendamos Eros Roberto GRAU, Ensaio e discurso sobre a interpretação/aplicação do direito, 4. ed. (São Paulo: 2006); Luis Roberto Barroso, Interpretação e aplicação da Constituição, 7. ed. (São Paulo: Saraiva, 2009); Luis Roberto Barroso, A nova interpretação constitucional, 3. ed. (São Paulo: Saraiva, 2008); Ingo W. Sarlet, A Eficácia dos direitos fundamentais, 10. ed. (Porto Alegre: Livraria do Advogado, 2010); Virgílio Afonso da Silva, coord., Interpretação constitucional (São Paulo: Malheiros, 2005); Peter Haberle, Hermenêutica constitucional (Porto Alegre: Fabris, 1997); Juarez Freitas, A interpretação sistemática da Constituição, 5. ed. (São Paulo: Malheiros, 2010); Lênio L. Streck, Jurisdição constitucional e hermenêutica, 2. ed. (Rio de Janeiro: Forense, 2003); Celso Ribeiro de Bastos, Hermenêutica e interpretação constitucional. 2. ed. (São Paulo: Instituto Brasileiro de Direito Constitucional, 1999); Marcelo A. C. de Oliveira, coord., Jurisdição e hermenêutica constitucional no Estado democrático de Direito (Belo Horizonte: Mandamentos, 2004); Aurélio A. V. Vieito, Da hermenêutica constitucional (Belo Horizonte: Del Rey, 2000).

28 Dworkin considera o ativismo judicial algo nocivo por representar a primazia das concepções subjetivas de justiça e de bem do próprio julgador: "O ativismo é uma forma virulenta de pragmatismo jurídico. Um juiz ativista ignoraria o texto da Constituição, a história de sua promulgação, as decisões anteriores da Suprema Corte que buscaram interpretá-la e as duradouras tradições de nossa cultura política. O ativista ignoraria tudo isso para impor a outros poderes do Estado seu próprio ponto de vista sobre o que a justiça exige. O direito como integridade condena o ativismo e qualquer prática de jurisdição constitucional que lhe esteja próxima”, Ronald Dworkin, O império do direito (São Paulo: Martins Fontes, 1999, p. 451-452).

29 Cf. Keenan M. Kmiec, op. cit., p. 1463-1466.

30 Idem, ibidem, p. 1466-1469.

31 Para maiores informações sobre o tema, ver William O. Douglas, Stare Decisis, Columbia Law Review, v. 49 , n. 6,1949 , p. $735-758$.

32 Ronald Dworkin, Uma decisão que ameaça a democracia, in: Juarez Freitas; Anderson V. Teixeira, orgs., Direito à democracia: estudos transdisciplinares (São Paulo: Conceito Editorial, 2011, p. 41).

33 Cf. Keenan M. Kmiec, op. cit., p. 1471-1473.

34 Idem, ibidem, p. 1473-1475.

35 Idem, ibidem, p. 1475-1476.

36 Cf. Eros Roberto Grau, op. cit., p. 247.

37 "O Direito a aplicar forma, em todas as hipóteses, uma moldura dentro da qual existem várias possibilidades de aplicação, pelo que é conforme ao Direito todo ato que se mantenha dentro deste quadro ou moldura, que preencha esta moldura em qualquer sentido possível.

"Se por 'interpretação' se entende a fixação por via cognoscitiva do sentido do objeto a interpretar, o resultado de uma interpretação jurídica somente pode ser a fixação da moldura que representa o Direito a interpretar e, consequentemente, o conhecimento das várias possibilidades que dentro desta moldura existem”, Hans Kelsen, Teoria pura do direito, 6. ed., 2. reimp. (São Paulo: Martins Fontes, 1999, p. 390).

38 Celso de Mello, Discurso proferido, em nome do Supremo Tribunal Federal, na solenidade de posse do Ministro Gilmar Mendes, na Presidência da Suprema Corte do Brasil, em 23.4.2008. Disponível em: www.stf.gov.br/arquivo/cms/noticiaNoticiaStf/anexo/discursoCM.pdf, p. 11.

39 Idem, ibidem, p. 12.

40 Para uma melhor análise sobre o deficit democrático do ativismo judicial, ver Luís Roberto Barroso, Judicialização, ativismo judicial e legitimidade democrática, RDE. Revista de Direito do Estado, v. 13, 2009, p. 71-91.

41 Apenas a título ilustrativo, veja-se que a judicialização é um fenômeno muito claramente sentido com o aumento, em progressão geométrica, do número de julgamentos realizados pelo STF: no ano de 1990, foram 
16.449 processos julgados, em 2000, o número passou para 86.138, chegando, em 2007, a 159.522 julgamentos, tendência de crescimento que só veio a ser controlada mediante expedientes limitativos, como as súmulas vinculantes, a vedação ao recurso repetitivo - no caso dos processos que poderiam passar antes pelo STJ - e a rigidez da necessidade de repercussão geral, por exemplo. Os dados citados são do site oficial do STF.

42 Sobre o interessantíssimo tema do decisionismo político, recomendamos Ronald Dworkin, O Direito com interpretação, in: Anderson V. Teixeira; Elton S. Oliveira, orgs., Correntes contemporâneas do pensamento jurídico (Barueri: Manole, 2009, p. 14-41), e também Lênio L. Streck, O que é isto - decido conforme minha consciência?, 3. ed. (Porto Alegre: Livraria do Advogado, 2011).

\section{REFERÊNCIAS BIBLIOGRÁFICAS}

ALEXY, Robert. Teoria de los Derechos Fondamentales. Madrid: Centro de Estudos Constitucionales, 1997. BARROSO, Luis Roberto. Interpretação e aplicação da Constituição. 7. ed. São Paulo: Saraiva, 2009. . A nova interpretação constitucional. 3. ed. São Paulo: Saraiva, 2008. - Judicialização, ativismo judicial e legitimidade democrática. RDE. Revista de Direito do Estado, v. 13, 2009, p. 71-91.

BASTOS, Celso Ribeiro de. Hermenêutica e interpretação constitucional. 2. ed. São Paulo: Instituto Brasileiro de Direito Constitucional, 1999.

BELAID, Sadok. Essai sur le Pouvoir Créateur et Normatif du Juge. Paris: Librairie Générale de Droit et de Jurisprudence, 1974.

BOBBIO, Norberto. O positivismo jurídico. São Paulo: Ícone, 1999.

CANOTILHO, José Joaquim Gomes. Direito Constitucional. 6. ed. Coimbra: Livraria Almedina, 1993. CAPPELLETTI, Mauro. Juízes legisladores? Porto Alegre: SAFE, 1999.

COVER, Robert M. The Origins of Judicial Activism in the Protection of Minorities. The Yale Law Journal, v. 91, 1982, p. 1287-1316.

DAY, John Cocchi. Retelling the Story of Affirmative Action: Reflections on a Decade of Federal Jurisprudence in the Public Workplace. California Law Review, v. 89, n. 1, 2001, p. 59-127.

DELGADO, José Augusto. Ativismo Judicial: o papel político do poder judiciário na sociedade contemporânea. In: FARIA, Juliana de Cordeiro et al. (Orgs.) Processo civil: novas tendências. homenagem ao Professor Humberto Theodoro Jr. Belo Horizonte: Del Rey, 2008.

DOUGLAS, William O. Stare Decisis. Columbia Law Review, v. 49, n. 6, 1949, p. 735-758.

DWORKIN, Ronald. Natural Law Revisited. University of Florida Law Review, v. 34, 1982, p. 165-188.

. Taking Rights Seriously. Londres: Duckworth, 1978.

. O império do direito. São Paulo: Martins Fontes, 1999.

. O Direito com interpretação. In: Anderson V. Teixeira; Elton S. Oliveira. (Orgs.) Correntes contemporâneas do pensamento jurídico. Barueri: Manole, 2009.

. Uma decisão que ameaça a democracia. In: Juarez Freitas; Anderson V. Teixeira. (Orgs.) Direito à

Democracia: estudos transdisciplinares. São Paulo: Conceito Editorial, 2011.

FREITAS, Juarez. Interpretação sistemática do direito. 5. ed. São Paulo: Malheiros, 2010.

GOMES, Joaquim Barbosa. Ação afirmativa \& princípio constitucional da igualdade. A experiência dos EUA. Rio de Janeiro: Renovar, 2001.

GRAU, Eros Roberto. Ensaio e discurso sobre a interpretação/aplicação direito. 4. ed. São Paulo: Malheiros, 2006. GUASTINI, Riccardo. Distinguendo: Studi di Teoria e Metateoria del Diritto. Torino: Giappichelli, 1996.

. Os princípios constitucionais como fonte de perplexidade. In: Anderson V. Teixeira; , Elton S.

Oliveira. (Orgs.) Correntes contemporâneas do pensamento jurídico. Barueri: Manole, 2009.

HABERLE, Peter. Hermenêutica constitucional. Porto Alegre: Fabris, 1997.

HONNETH, Axel. La Réification. Petit Traité de Théorie Critique. Paris: Gallimard, 2007.

KELSEN, Hans. Teoria pura do direito. 6. ed. 2. reimp. São Paulo: Martins Fontes, 1999.

KILLENBECK, Mark R. Pushing Things up to Their First Principles: Reflections on the Values of Affirmative Action. California Law Review, v. 87, n. 6, 1999, p. 1299-1407.

KMIEC, Keenan D. The Origin and Current Meaning of "Judicial Activism". California Law Review, v. 92, n. 5, 2004, p. 1441-1477. 
MARSHALL, William P. Conservatives and the seven sins of judicial activism. University of Colorado Law Review, v. 73, n. 4, 2002, p. 101-140.

MELLO, C. de. 2008. Discurso proferido, em nome do Supremo Tribunal Federal, na solenidade de posse do Ministro Gilmar Mendes, na presidência da Suprema Corte do Brasil, em 23.4.2008. Disponível em: www.stf.gov.br/arquivo/cms/noticiaNoticiaStf/anexo/discursoCM.pdf.

MOSES, Michele. Affirmative Action and the Creation of More Favorable Contexts of Choice. American Educational Research Journal, v. 38, n. 1, 2001, p. 3-36.

OLIVEIRA, Marcelo A. C. de. (Coord.) Jurisdição e hermenêutica constitucional no Estado democrático de Direito. Belo Horizonte: Mandamentos, 2004.

RAMOS, Elival da Silva. Ativismo judicial: parâmetros dogmáticos. São Paulo: Saraiva, 2010.

SARLET, Ingo W. A Eficácia dos direitos fundamentais. 10. ed. Porto Alegre: Livraria do Advogado, 2010. SILVA, Virgílio Afonso da. (Coord.) Interpretação constitucional. São Paulo: Malheiros, 2005.

STRECK, Lênio L. O que é isto - Decido conforme minha consciência? 3. ed. Porto Alegre: Livraria do Advogado, 2011.

. Jurisdição constitucional e hermenêutica. 2. ed. Rio de Janeiro: Forense, 2003.

SUSTEIN, Cass R. Lochner's Legacy. Columbia Law Review, v. 87, n. 5, 1987, p. 873-919.

TEIXEIRA, Anderson V.; OLIVEIRA, Elton S. (Orgs.) Correntes contemporâneas do pensamento jurídico. Barueri: Manole, 2009.

VALLINDER, Torbjörn. The Judicialization of Politics - A Word-wide Phenomenon: Introduction. International Political Science Review, v. 15, n. 2, 1994, p. 91-99.

VIEITO, Aurélio A. V. Da hermenêutica constitucional. Belo Horizonte: Del Rey, 2000.

ZAGREBELSKY, Gustavo. La Legge e la sua Giustizia. Bologna: Il Mulino, 2008. Il Diritto Mite. Torino: Einaudi, 1992.

\section{Anderson Vichinkeski Teixeira}

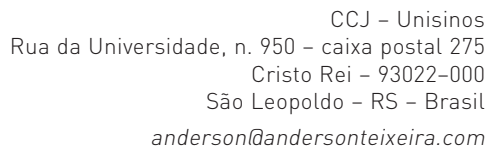

DOUTOR EM TEORIA E HISTÓRIA do DiREITO PELA UNIVERSITÀ DEGLI STUdI DI FIRENZE (ITÁLIA) ESTÁGIO PÓS-DOUTORAL NA UNIVERSITÀ DEGLI STUDI DI FIRENZE, ITÁLIA

Mestre em Direito do Estado Pela Puc/RS

Professor do Programa de Pós-Graduação em Direito (Mestrado/Doutorado) na UNIVERSIDADE DO VALE DOS SINOS (UNISINOS) 